\title{
Retraction notice to: "Cutting ceramic inserts: the influence of abrasive machining and surface coatings on the operational characteristics"
}

Refers to

RETRACTED: Cutting ceramic inserts: the influence of abrasive machining and surface coatings on the operational characteristics, Marina Volosova and Sergey Grigoriev, Mechanics \& Industry, Volume 17, Number 7, 2016, published online on 23 December 2016

DOI: $10.1051 / \mathrm{meca} / 2016074$

\begin{abstract}
At the request of the Authors, the following article has been retracted: It has come to the attention of the journal and EDP Sciences that a similar version of the article has been previously published in another journal. The Editorial Board of Mechanics \& Industry and EDP Sciences have agreed to retract the article (please see 'Policies for publication of errata and for article retraction at http:// ww. mechanics-industry.org/about-the-journal/ethical-standards) at the request of the authors as explained here below.
\end{abstract}

Dear Editorial board,

It has come to our attention that the paper authored Prof. Dr. S.N. Grigoriev and Dr. M.A. Volosova and published in the Journal Mechanics \& Industry in December 2016 [1] contains large portions from another article [2], published by extended board of same authors in 2014. In fact, it happend by an unattentive mistake on the stage of correction of text from the side of authors. On some stage the original text of the article, which gives detalied and never printed data, was replaced by the previous already published work and it was not noticed in the period of prepublishing. As the article was already published it was recognized as self-plagiarism by the authors, but it was not an intention of the experieced authors. The authors kindly ask the editors of the Journal Mechanics \& Industry to retract the published article from international bibliographic data bases.

The authors apologize to the editors of the Journal Mechanics \& Industry and to the international research community.

\section{References}

[1] M. Volosova, S. Grigoriev, Cutting ceramic inserts: the influence of abrasive machining and surface coatings on the operational characteristics, Mechanics \& Industry 17 (2016) 705

[2] S. Grigoriev, M. Volosova, Y. Melnik, N. Cherkasova, A. Gurkina, Cutting Ceramic Materials: Influence of Abrasive Machining and Coating Deposition on the Perfomance Potential, Adv. Mater. Res. 1025-1026 (2014) 317-324 